Provided by the author(s) and University of Galway in accordance with publisher policies. Please cite the published version when available.

\begin{tabular}{|c|c|}
\hline Title & $\begin{array}{l}\text { Broadband dielectric properties of adrenal gland for accurate } \\
\text { anatomical modelling in medical applications }\end{array}$ \\
\hline Author(s) & $\begin{array}{l}\text { Shahzad, Atif; Clausing, D.; Prakash, Punit; Dennedy, Michael } \\
\text { C.; O'Halloran, Martin }\end{array}$ \\
\hline $\begin{array}{l}\text { Publication } \\
\text { Date }\end{array}$ & 2017-09-11 \\
\hline $\begin{array}{l}\text { Publication } \\
\text { Information }\end{array}$ & $\begin{array}{l}\text { Shahzad, Atif, Clausing, D., Prakash, Punit, ,Dennedy, Michael } \\
\text { C., O'Halloran, Martin (2017), Broadband dielectric properties } \\
\text { of adrenal gland for accurate anatomical modelling in medical } \\
\text { applications. Paper presented at } 2017 \text { International Conference } \\
\text { on Electromagnetics in Advabced Applications (ICEAA), } \\
\text { Verona, Italy, 11-15 September, } \\
\text { doi:10.1109/ICEAA.2017.8065558 }\end{array}$ \\
\hline Publisher & IEEE \\
\hline $\begin{array}{l}\text { Link to } \\
\text { publisher's } \\
\text { version }\end{array}$ & https://dx.doi.org/10.1109/ICEAA.2017.8065558 \\
\hline Item record & http://hdl.handle.net/10379/15155 \\
\hline DOI & http://dx.doi.org/10.1109/ICEAA.2017.8065558 \\
\hline
\end{tabular}

Downloaded 2023-04-26T13:00:47Z

Some rights reserved. For more information, please see the item record link above. 


\section{Broadband Dielectric Properties of Adrenal Gland for Accurate Anatomical Modelling in Medical Applications}
A. Shahzad ${ }^{1}$
D. Clausing ${ }^{2}$
P. Prakash ${ }^{2}$
M. C. Dennedy ${ }^{3}$
M. O’Halloran ${ }^{1,3}$

\begin{abstract}
Dielectric properties of biological tissue are important in safety assessment and evaluation of novel medical imaging and therapeutic devices. This paper reports frequency dependent dielectric properties of adrenal tissue, which is a potential target for microwave ablative therapy to treat benign and malignant adrenal tumors. Dielectric properties of bovine adrenal glands were measured using open-ended coaxial probe over 0.5 to $20 \mathrm{GHz}$, and a two pole Cole-Cole model was fitted to the measured data. The parameters of Cole-Cole model are presented in this paper.
\end{abstract}

\section{INTRODUCTION}

The dielectric properties of biological tissue are important in modelling and evaluating the energy deposition in a body exposed to radio waves. There has been a number of studies reporting dielectric properties of various animal and human tissue over a wide frequency range of $10 \mathrm{~Hz}$ to $100 \mathrm{GHz}$ [1-10]. Although dielectric data of most of the body tissues are available in the literature, there are some tissues that have received little attention due to lack of demanding applications. With increasing interest in electromagnetic therapeutic interventions, accurate knowledge of dielectric properties of these body tissues has become important. In recent years, several radio-wave medical imaging and therapeutic systems have been developed, with radio-wave ablation being one of the most notable development to treat cancerous lesions in the human body. Radio-wave thermal ablation has been investigated for minimally invasive treatment of adrenal adenomas [11-12]. The development of ablative therapy for adrenal adenomas require accurate knowledge of dielectric properties of the adrenal gland. However, there is very limited data available on the dielectric properties of the adrenal gland. To best of our knowledge, there is only one study [13] to date in literature where the dielectric properties of outer layer of the porcine adrenal gland (cortex) were measured. Based on the anatomy of adrenal gland, there are two distinct tissue layers in the gland, referred as adrenal cortex, and medulla. Therefore, it is necessary to measure the dielectric properties of both tissue layers for anatomically accurate modelling of the adrenal gland.

This paper presents parameters of two pole ColeCole models fitted to the measured dielectric properties of cortex and medulla of bovine adrenal gland. The remainder of this paper is organized as follows: Section 2 details the materials, measurement method and uncertainty, and the Cole-Cole model. Measured data and the parameters of Cole-Cole model are presented in section 3 , while the conclusions are presented in section 4 .

\section{MATERIALS AND METHODS}

\subsection{Tissue Samples}

The bovine adrenal samples $(n=12)$ were obtained from a local abattoir, within 2 hours post mortem. The samples were kept inside the peri-adrenal fat and removed at the time of measurements to avoid excessive dehydration. The temperature of the glands at the time of measurement was recorded at each site of measurement and found in the range of normal room temperature $\left(22^{\circ} \mathrm{C} \pm 0.8\right)$. The interior of the adrenal gland was accessed through a cross sectional cut, and measurements were performed on internal surface of the tissue to minimize the effect of surface dehydration [14]. Fig. 1 shows one of the adrenal gland samples and the measurement sites on the cortical and medullary tissues.

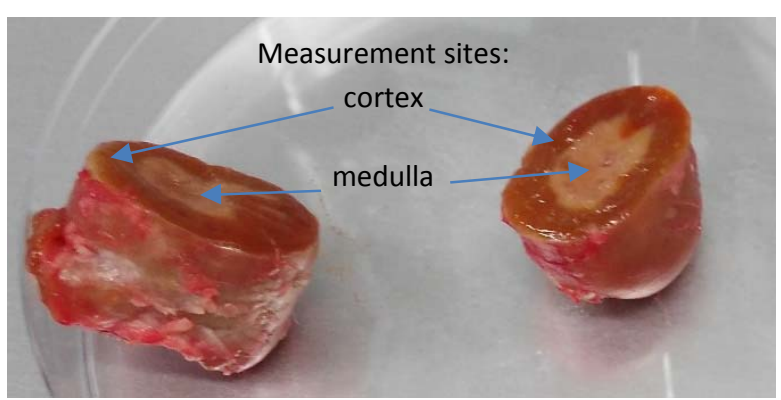

Figure 1: Cross sectional photograph of the adrenal gland, showing cortex and medulla.

\subsection{Dielectric Measurements}

Measurements were performed using a slim-form dielectric probe (Keysight 85070E, Santa Rosa, CA, USA) connected to a vector network analyzer (Keysight E8362B), and reflection coefficient (S11) was recorded at 101 linearly spaced discrete frequency points over 0.5 to $20 \mathrm{GHz}$. The S11 parameters were converted to complex permittivity using Keysight material measurement software suite (Keysight N1500A). The tissue sample was pressed against the probe using a lab jack to achieve good contact for measurements. The samples were kept inside the periadrenal fat in a sealed bag, and removed at the time of measurements. Interior of the gland was exposed with a cross sectional cut to perform three measurements on

\footnotetext{
${ }^{1}$ Dept. of Electrical and Electronic Engineering, National University of Ireland, Galway, Ireland, e-mail: atif.shahzad@nuigalway.ie, te: +353838422754.

${ }^{2}$ Dept. of Electrical and Computer Engineering, Kansas State University, Manhattan, KS, USA..

${ }^{3}$ School of Medicine, National University of Ireland Galway, Ireland.
} 
each tissue (adrenal cortex and medulla). Total of 36 broadband measurements were performed on 12 adrenal glands for each tissue type (cortex and medulla).

\subsection{Measurement Uncertainty}

Accuracy of the measurement system was evaluated on $0.1 \mathrm{M} \mathrm{NaCl}$ solution (Honeywell chemicals, Fluka 35275), using the standard analysis technique described in [15]. Total uncertainty of the measurement system was estimated by repeated measurements to assess random and systematic errors. The error was calculated for each discrete frequency point in the measurement and averaged over the measurement frequency band. Table 1 lists the random and systematic errors in the system, assessed over $0.1 \mathrm{M} \mathrm{NaCl}$ solution at $22^{\circ} \mathrm{C}$. The accuracy of the measurement system was calculated as deviation from the reference data obtained from the Cole-Cole model presented in Peyman et al. [16].

\begin{tabular}{|c|c|c|}
\hline Uncertainty & $\begin{array}{c}\text { Dielectric } \\
\text { constant } \\
(\%)\end{array}$ & $\begin{array}{c}\text { Conductivity } \\
(\%)\end{array}$ \\
\hline Repeatability & 0.31 & 0.75 \\
\hline Accuracy & 0.65 & 1.57 \\
\hline Drift & 0.03 & 0.06 \\
\hline Combined uncertainty & 0.72 & 1.74 \\
\hline
\end{tabular}

Table 1: Measurement uncertainty of the system evaluated on standard liquid ( $0.1 \mathrm{M} \mathrm{NaCl}$ solution).

Fig. 2 shows a comparison of the dielectric properties of $0.1 \mathrm{M} \mathrm{NaCl}$ solution measured in this study and the reference data obtained from Cole-Cole model in [16]. Measured data is found to be in agreement with the reference data with average error less than $2 \%$.

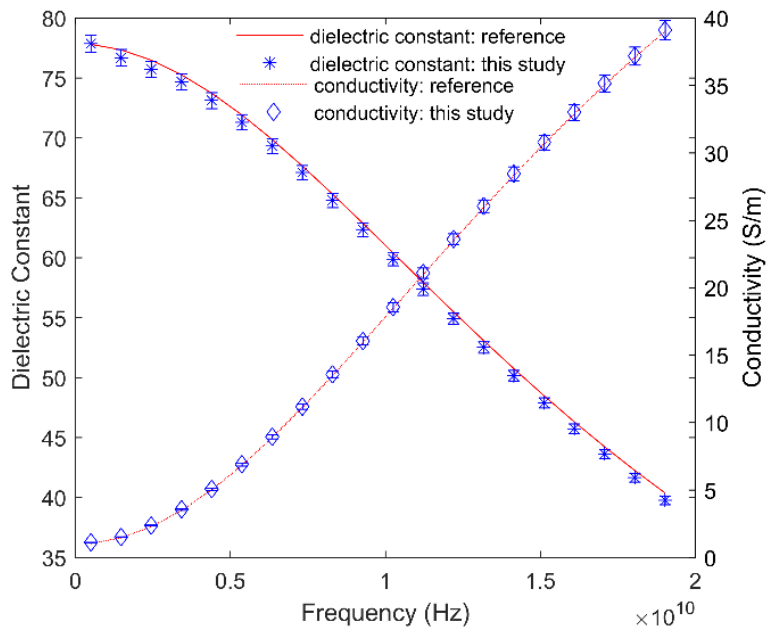

Figure 2: Comparison of measured dielectric properties of $0.1 \mathrm{M} \mathrm{NaCl}$ solution with reference [16].
The broadband dielectric properties are generally expressed in the form of a parametric model. ColeCole model is commonly used to represent the frequency dependent permittivity of biological tissues. In the Cole-Cole mode, the frequency dependent complex permittivity is represented as:

$$
\varepsilon(\omega)=\varepsilon_{\infty}+\sum_{n=1}^{N} \frac{\Delta \varepsilon_{n}}{1+\left(j \omega \tau_{n}\right)^{1-\alpha_{n}}}+\frac{\sigma_{s}}{j \omega \varepsilon_{0}}
$$

Where $\varepsilon_{\infty}$ is the permittivity at highest frequency; $\Delta \varepsilon_{n}$ is the magnitude of $n^{\text {th }}$ relaxation; $\omega$ is angular frequency in radians per second; $\tau_{n}$ is relaxation time of $n^{\text {th }}$ relaxation; $\alpha_{n}$ is an empirical parameter that accounts for broadening of $n^{\text {th }}$ relaxation; $\sigma_{s}$ is static conductivity; and $\varepsilon_{0}$ is absolute permittivity.

\section{RESULTS AND DISCUSSION}

The frequency dependent permittivity of the adrenal tissues was measured on the interior of freshly sliced gland. Fig. 3 shows the measured dielectric constant (Fig. 3-A) and effective conductivity (Fig. 3B) of the adrenal cortex and medulla. To produce a less cluttered plot, only 21 evenly spaced frequency points are shown on the Fig. 3. For a comparison, the dielectric properties of adrenal gland (cortex) of a porcine from Peyman et al. [13] are also shown on the Fig. 3. The effective conductivity of cortex measured in this study closely aligns with [13]; however, a relatively large difference is found in the dielectric constant of the cortex on high frequencies. Since the dielectric constant of cortex and medulla measured in this study follows similar frequency dependent behavior, the difference between the dielectric constant in this study and Peyman et al. [13] on high frequencies may be associated to the fitting error.

The measured dielectric data was fitted to a two pole Cole-Cole model, and the parameters of the model are listed in Table 2. A weighted nonlinear least square method was used to fit the data with a fitting error threshold of $10^{-4}$.

\begin{tabular}{|c|c|c|}
\hline Parameter & Adrenal Cortex & Adrenal Medulla \\
\hline$\varepsilon_{\infty}$ & 3.57 & 3.88 \\
\hline$\Delta \varepsilon_{1}$ & 47.08 & 52.95 \\
\hline$\tau_{1}$ & $8.33 \mathrm{ps}$ & $7.01 \mathrm{ps}$ \\
\hline$\alpha_{1}$ & 0.16 & 0.17 \\
\hline$\Delta \varepsilon_{2}$ & 52.31 & 62.05 \\
\hline$\tau_{2}$ & $1.69 \mathrm{~ns}$ & $4.28 \mathrm{~ns}$ \\
\hline$\alpha_{2}$ & 0.03 & 0.14 \\
\hline$\sigma_{\mathrm{s}}$ & 0.46 & 0.62 \\
\hline
\end{tabular}

Table 2: Parameters of the two pole Cole-Cole model fitted to the measured data of Adrenal tissues.

\subsection{Cole-Cole Model}



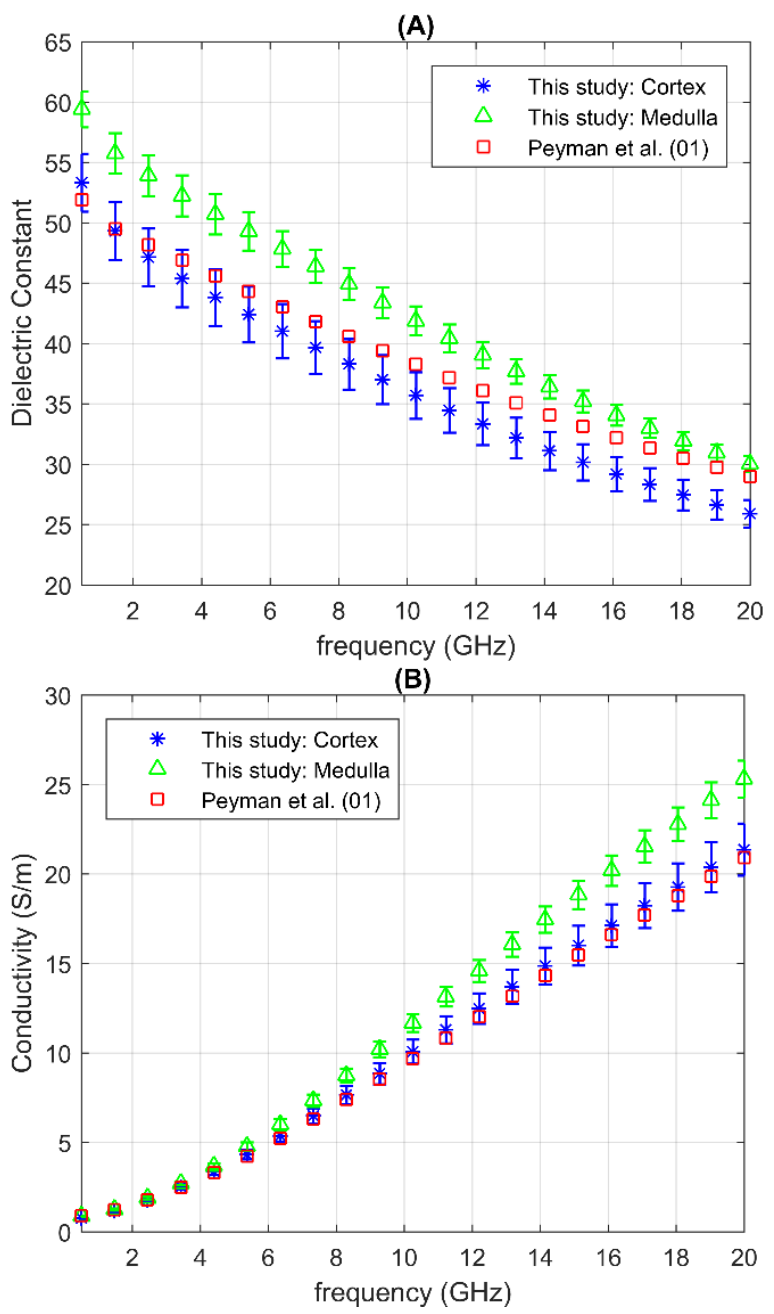

Figure 3: Measured dielectric constant (A) and conductivity (B) of adrenal tissues: a comparison with existing data [13]. Error bars show standard deviation of the measured data.

\section{CONCLUSIONS}

The dielectric properties of adrenal gland were measured over frequency range of 0.5 to $20 \mathrm{GHz}$. A two pole Cole-Cole model was fitted to the measured data, and parameters of the model are reported in this paper. The dielectric data presented in this paper can be used to produce anatomical accurate models for evaluation of novel medical imaging and therapeutic devices, particularly in development of microwave ablative therapy for adrenal tumors.

\section{Acknowledgments}

The research leading to these results has received funding from the European Research Council under the European Union's Horizon 2020 Programme/ERC Grant Agreement BioElecPro n. 637780, Science Foundation Ireland Grant n. 15/ERCS/3276, and Irish Research Council New Foundations Award.

\section{References}

[1] T. England, "Dielectric properties of the human body for wave-lengths in the $1-10 \mathrm{~cm}$. range," Nature, vol. 166, no. 4220, pp. 480-481, 1950.

[2] H. P. Schwan, "Electrical properties of tissue and cell suspensions," Advances in biological and medical physics, vol. 5, p. 147, 1957.

[3] R. D. Stoy, K. R. Foster, and H. P. Schwan, "Dielectric properties of mammalian tissues from 0.1 to $100 \mathrm{MHz}$; a summary of recent data." Physics in medicine and biology, vol. 27, no. 4, p. 501, 1982.

[4] M. A. Stuchly, A. Kraszewski, S. S Stuchly, and A. M. Smith, "Dielectric Properties of Animal Tissues in Vivo at Radio and Microwave Frequencies: Comparison between Species." Physics in Medicine and Biology, vol. 27, no. 7, p. 927, 1982.

[5] A. Surowiec, S. S. Stuchly, L Eidus, and A Swarup, "In Vitro Dielectric Properties of Human Tissues at Radiofrequencies." Physics in Medicine and Biology, vol. 32, no. 5, p. 615, 1987.

[6] S. Gabriel, R. W. Lau, and C. Gabriel, "The dielectric properties of biological tissues: II. Measurements in the frequency range $10 \mathrm{~Hz}$ to 20 GHz." Physics in medicine and biology, vol. 41, no. 11, p. 2251, 1996.

[7] M. Lazebnik, D. Popovic, L. McCartney, C. B. Watkins, M. J. Lindstrom, J. Harter, S. Sewall et al. "A large-scale study of the ultrawideband microwave dielectric properties of normal, benign and malignant breast tissues obtained from cancer surgeries." Physics in medicine and biology, vol. 52, no. 20, p. 6093, 2007.

[8] A. P. O'Rourke, M. Lazebnik, J. M. Bertram, M. C. Converse, S. C. Hagness, J. G. Webster, and D. M. Mahvi, "Dielectric properties of human normal, malignant and cirrhotic liver tissue: in vivo and ex vivo measurements from 0.5 to $20 \mathrm{GHz}$ using a precision open-ended coaxial probe." Physics in medicine and biology, vol. 52, no. 15 , pp. $4707-$ 19, 2007.

[9] L. Abdilla, C. Sammut, and L. Z. Mangion, "Dielectric properties of muscle and liver from 500 MHz-40 GHz," Electromagnetic Biology and Medicine, vol. 32, no. 2, pp. 244-252, 2013.

[10] A. Peyman, S. Holden, and C. Gabriel, "Measurement of the Dielectric Properties of Biological Tissues in vivo at Microwave Frequencies," Tech. Rep., 2009.

[11] R. Zener, A. Zaleski, S.H. Van Uum, D.K. Gray, and A. Mujoomdar, "Successful percutaneous CTguided microwave ablation of adrenal gland for ectopic Cushing syndrome." Clinical Imaging, vol. 42, pp.93-95, 2017.

[12] H. Fallahi, A. Shahzad, D. Clausing, M. O'Halloran, M. C. Dennedy, and P. Prakash. 
"Technological requirements for microwave ablation of adrenal masses." In Antennas and Propagation (EUCAP), 11 th European Conference on, pp. 3713-3716, 2017.

[13] A. Peyman, and C. Gabriel, "Dielectric properties of porcine glands, gonads and body fluids.", Physics in medicine and biology, vol. 57, no. 19, p. 339, 2012.

[14] A. Shahzad, S. Khan, M. Jones, R. M. Dwyer, and M. O'Halloran, "Investigation of the effect of dehydration on tissue dielectric properties in ex- vivo measurements." Biomedical Physics \& Engineering Express, vol. 3, 2017.

[15] C. Gabriel, and A. Peyman, "Dielectric measurement: error analysis and assessment of uncertainty." Physics in Medicine and Biology, vol. 51, no. 23, p. 6033, 2006.

[16] A. Peyman, C. Gabriel, and E.H. Grant, "Complex permittivity of sodium chloride solutions at microwave frequencies.", Bioelectromagnetics, vol. 28, no. 4, p. 264, 2007. 